\title{
INCLUSÃO DOS ALUNOS COM DEFICIÊNCIA NAS ESCOLAS
}

\section{ARTIGO ORIGINAL}

PERES, Sidneis Queiroz ${ }^{1}$

MARTINS, Edson ${ }^{2}$

PERES, Sidneis Queiroz. MARTINS, Edson. Inclusão dos alunos com deficiência nas escolas. Revista Científica Multidisciplinar Núcleo do Conhecimento. Ano 06, Ed. 01, Vol. 07, pp. 90-101. Janeiro de 2021. ISSN: 2448-0959, Link de acesso: https://www.nucleodoconhecimento.com.br/educacao/inclusao-dos-alunos

\section{RESUMO}

A educação inclusiva no Brasil por muito tempo era feita em centros especializados em alunos com deficiência, mas há alguns anos atrás esses alunos passaram a ter o direito de se matricular nas escolas regulares, mas, muitas eram as dificuldades encontradas por eles ao ser inserido no ambiente escolar totalmente sem estrutura para recebê-los, e a falta de profissionais qualificados para trabalhar com esse aluno, também era preocupante. $O$ artigo tem como objetivo geral a compreensão do processo de inclusão dos alunos com deficiências nas escolas regulares, e para isso, foram realizadas pesquisas em várias obras publicadas sobre 0 assunto de vários autores, o que ajudou e muito no desenvolvimento do artigo. Nota se que ainda há muito a ser feito para a melhoria deste processo de ensino e aprendizagem dos alunos com deficiência nas unidades escolares. Nas considerações finais, foi dado algumas sugestões de melhoria neste processo de inclusão dos alunos com deficiências nas escolas regulares, como por exemplo, a regulamentação do cargo desse profissional que irá trabalhar com esse aluno, pois, em muitos estados e municípios essa função

\footnotetext{
${ }^{1}$ Licenciatura em Pedagogia e Tecnólogo em Gestão Pública.

2 Orientador. Pedagogo, especialista em EAD, mestre em Educação, doutor em Ciências da Religião. Professor na Faculdade FAE.
} 
não está regulamentada em sua respectiva lei orgânica, e a criação de concurso público para o cargo específico, já a parte estrutural as escolas, estão sendo readequadas para atender esses alunos.

Palavras-Chave: Inclusão escolar, deficiência mental, processo de ensino aprendizagem.

\section{INTRODUÇÃO}

A escolha do tema se deu através da necessidade de um melhor atendimento aos alunos com deficiência no ambiente escolar e que quase sempre conta com profissionais despreparados para trabalhar com essas crianças, pois, não recebiam nenhum tipo de formação o que deixou o trabalho deles muito a desejar no início.

A pesquisa sobre o tema fez se necessário, pois o número de alunos inclusos vem crescendo muito no decorrer dos anos e muitas escolas ainda não estão preparadas para recebê-los de forma adequada tanto na parte estrutural como na parte profissional e psicológicas dos profissionais das unidades escolares que por muitas das vezes nunca trabalhou com alunos com deficiência.

Este artigo é o resultado de uma pesquisa bibliográfica em cima das obras de alguns autores sobre o processo de inclusão dos alunos com deficiências na escola de ensino regular, processo esse que vem sendo modificado muito com o passar dos anos, buscando sempre a melhoria no atendimento dos alunos com deficiência nas escolas, serão utilizados artigos científicos, revista e livros publicados na internet, leis e decretos publicados pelo poder público na internet.

Este artigo tem como objetivo compreender o processo de inclusão e do ensino aprendizagem dos alunos com deficiência nas escolas e salientar a todas as autoridades e a comunidade em geral sobre a importância dos mesmos e buscar com isso a oferta de uma estrutura escolar de qualidade que possa atender a expectativa de um ensino de qualidade a todos os alunos sem exceção e ao seu pleno desenvolvimento. 
O artigo foi dividido em seis partes, sendo a primeira parte esta introdução que traz uma prévia do artigo, e a segunda o desenvolvimento que trata do assunto estudado com mais aprofundamento, já a terceira parte trata dos objetivos do artigo, a quarta parte trata da fundamentação teórica do artigo, e a quinta partes são as considerações finais que traz observações e sugestões de melhoria nesse processo de inclusão e na sexta e última parte trata se das referências bibliográficas do artigo.

\section{ASPECTOS HISTÓRICOS DA INCLUSÃO ESCOLAR}

Pode se dizer que as políticas inclusivas dos alunos com deficiências originaram se em 1968, depois que a UNESCO, juntou se com grandes especialistas e a partir daí surgiu um programa que buscava o atendimento dos alunos que tem deficiênciagarantindo assim as bases que iram conceituar o que hoje já é chamado de Educação Especial. Destaco um dos trechos do referido documento, é observado que:

Os objetivos da Educação Especial destinada às crianças com deficiências mentais, sensoriais, motoras ou afetivas são muito similares aos da educação geral, quer dizer: possibilitar ao máximo o desenvolvimento individual das aptidões intelectuais, escolares e sociais. (UNESCO, 1968, p. 12)

Já, na década de 1970, países com práticas mais consolidadas sobre o assunto decidiram colocar em prática algumas iniciativas, Santos em 1997, diz que ações de mobilizações foram desencadeadas em vários países no continente europeu depois disso houve o surgimento da chamada "filosofia da inclusão", ainda neste mesmo ano de 1960 do século passado. Mas ainda serão necessários muitos e muitos anos para que a literatura (MADER, 1997; JÖNSSON, 1994 e outros) possa se tornar evidente no âmbito internacional.

Entende ser que para haver uma mudança em algo é necessário um estimulo que provoque essa mudança, pois, se não fosse o interesse de mudança nesse contexto de inclusão esse processo de inclusão estaria ainda estagnado nos mesmos moldes do passado, dificultando assim o acesso desses alunos com deficiências nas unidades escolares, e com a necessidade de um olhar diferenciado para com esses alunos, a 
comunidade em geral passou a questionar aquela visão tradicional que não condizia mais com a realidade, como veremos a seguir;

De acordo com Reis e Boss, (2008, p. 3-4)

O que levou ao estímulo original desse contexto foi o questionamento da visão tradicional e profundamente enraizada na sociedade, que já via a necessidade de uma integração com a responsabilidade a ser assumida, literalmente, pela pessoa com necessidades especiais dispensando, a sociedade de participar desse processo. É esta concepção que vai perder força. Ideias relativas à normalização e integração, que antes eram predominantes, foram sendo substituídas pelo princípio do combate sistemático de qualquer tipo de exclusão social da pessoa com deficiência.

Como foi visto no trecho citado acima a ideia que se tinha no passado era que as pessoas com deficiências era um "problema da família", mas, com o passar do tempo essa visão vem sendo diluída dentro da sociedade em geral onde todos tem um pouquinho de responsabilidade para com os alunos com necessidades especiais, pois, se tratando de um ser humano merece todo carinho e respeito de todos garantindo assim todos os seus direitos.

Baroni (2007) fala sobre os importantes avanços alcançados pelo Brasil diante deste assunto, mas, nos alerta; que o país precisa evoluir e muito em sua legislação e também sobre o posicionamento de cada cidadão sobre o tema.

Em 1999, foi elaborada a convenção interamericana para eliminação de todas as formas de discriminação contra as pessoas com deficiência e que foi sancionada no Brasil através do decreto ํㅡㄴ 3,956 de setembro de 2001, onde o país assumiu muitos compromissos e traçou metas para alcançar os objetivos propostos. Sendo assim pode se dizer que através de uma avaliação simples das metas alcançadas até hoje, pode se perceber que o Brasil teve muitos avanços na efetivação e construção de política pública inclusiva, porém, ainda há muito a ser feito, e para isso é necessário intensificar o empenho de todos os órgãos tanto governamentais como 0 não governamentais, para que se possam alcançar resultados ainda melhores, diante de 
um tema de tamanha importância para a comunidade escolar em geral. (BARONI, 2007)

\section{PARADIGMAS DA INCLUSÃO}

$\mathrm{Na}$ antiguidade antes de Cristo as pessoas com deficiências eram visto com maus olhos, pois, as pessoas via a deficiência como uma forma de punição de Deus pelos pecados da pessoa com deficiência ou de seus pais e diante disso as pessoas com deficiências sofriam muito preconceito da sociedade e isso aconteceu por muitos e muitos anos, por este motivo as famílias que tinham filhos com deficiência preferiam manter seus filhos em casa isolados da sociedade para evitar que seus filhos passassem por humilhação diante da sociedade, mas, com o passar dos séculos esse paradigma de que a deficiência era castigo de Deus foi sendo quebrado. Bíblia (João 9:2-3)

E com essa quebra de paradigma a relação da pessoa com deficiência melhorou e muito é claro que ainda a pessoas que mesmo de forma indireta agem de forma preconceituosa com pessoas portadoras de deficiência, mais, isso tem melhorado e muito, nos tempos atuais as pessoas passaram a aceitar a pessoa com deficiência como parte da sociedade, e vem buscando incluir de forma geral no seio da sociedade, onde tem os mesmo direito de todos, mas, focando na educação, há grandes avanços que melhorou e muito o acesso ao ambiente escolar. (MACIEL, 2000, p. 1).

Isso leva a necessidade de se pensar nas questões de acesso e na qualidade na educação, buscando assim a atenção dos sistemas de ensino para a necessidade de uma reorganização dos espaços educacionais a partir de uma visão mais abrangente do currículo, com o intuito de eliminação das barreiras e obstáculos que dificultam ou impedem a participação e a aprendizagem das pessoas que estão inclusas na escola. Neste sentido, toda política pública voltada para a educação inclusiva pressupõe a criação e o desenvolvimento de ações estruturadas para atender as necessidades de cada aluno neste processo, dentre as ações está a ampliação da oferta de recursos e serviços para que se possa garantir as condições de acessibilidade das pessoas com necessidades especiais nas instituições de ensino. 
Pois a unidade precisa se adequar para receber esses alunos e garantir o bem estar e a segurança de todos, para isso é necessário a construções de rampas, colocação piso tátil, corrimãos e adaptação do banheiro para os alunos com necessidades especiais da unidade escolar, bem como a remoção de todo e qualquer obstáculos que venha a dificultar a passagem dos alunos, e os materiais didáticos deve ser adaptado para o aluno de acordo com sua deficiência.

Alves (2006, p. 3) diz que:

O princípio da acessibilidade está presente na concepção que orienta a construção da escola inclusiva, indicando a sua dimensão transversal que contrapõe a existência de sistemas paralelos de ensino especial e ensino regular e passa a planejar as escolas com ambientes acessíveis e sem discriminação, que garantamos direitos de cidadania e atenção à diversidade humana.

Este princípio é muito importante para o processo de inclusão dos alunos com deficiências nas escolas, pois, trata se de orientações de adequações das unidades escolares já existentes e do planejamento de construções das novas escolas dentro dos padrões de inclusão para receber os alunos com deficiências, onde a unidade deve atender vários requisitos para se tornar uma escola de inclusão.

O professor deve trabalhar de forma diferenciada com cada aluno incluso, como uma atividade de colorir ou algo que venha a chamar a atenção do aluno, não tomar do aluno com deficiência aquele brinquedo que the traz calma, pois isso poderá deixar o aluno ainda mais suscetível a uma crise momentânea isso claro dependendo da deficiência ou do grau de deficiência de cada aluno.

Por isso o correto é Incentivar os colegas a interagir e não deixar o aluno com deficiência isolado, pois o mesmo também necessita de interagir com outras crianças para se desenvolver melhor as suas habilidades psíquicas e motoras no ambiente escolar, mesmo quando o aluno incluso não brinca é importante que o mesmo esteja junto com os demais alunos nas atividades tanto no interior da sala de aula como nas aulas fora de sala, pois, esse momento é muito importante, mesmo que a deficiência do aluno o impossibilite a sua interação com os demais alunos é importante que ele 
esteja junto com os alunos nas brincadeiras mesmo que só olhando, pois, isso pra muitos alunos inclusos já é muito gratificante e no ambiente escolar o seu cuidador deve estar a tento a isso.

No âmbito do ensino público, onde o governo fornece um cuidador individual para cada aluno com deficiência, durante o processo de contratação devem ser selecionadas pessoas capacitadas para trabalhar com a criança, saber sua rotina, gostos e estratégias sobre como manter a criança calma, e principalmente saber como agir no momento de crise da criança, pois, sabe se que existem muitos tipos de deficiência e algumas delas pode deixar a pessoa com essa deficiência sujeita a crises momentâneas que podem o deixar até mesmo violento com outras pessoas e a si mesmo e esse profissional deve estar preparado para saber lidar com este tipo de situação, porque até mesmo entre as crianças sem deficiência essa questão de violência pode acontecer, mas, o profissional deve estar sempre atento ao seu aluno, pois, dependendo de sua deficiência ele não terá nenhuma noção de perigo e facilmente poderá se ferir.

O processo de inclusão dos alunos com deficiência nas escolas é algo que vem a garantir o direito de cada brasileiro que é o de frequentar uma sala de aula comum, junto com os demais alunos onde o mesmo possa permanecer e interagir com a turma e com a escola em geral, pois, parte se do princípio constitucional onde diz que todos devem ser tratados de forma igualitária.

A pesquisa sobre o tema fez se necessário, pois o número de alunos inclusos vem crescendo muito e muitas escolas ainda não estão preparadas para recebê-los de forma adequada.

"Desculpe não estamos preparados para receber seu filho" essa é a resposta que muitos pais ouvem quando tentam matricular seus filhos com deficiência em uma escola regular. Porém não dá mais para aceitar esse tipo de resposta por parte das escolas e ficar calados. Faz se necessário aprofundar um pouco mais sobre o assunto e conscientizar os profissionais envolvidos no processo de ensino aprendizagem que 
se cumpra o que está garantido em Lei sobre a inclusão. Esta é a contribuição que esta pesquisa poderá trazer para o meio acadêmico e para a comunidade em geral.

Na cidade de Cuiabá capital do estado de Mato Grosso, pode ser observado que todas as unidades escolares foram adequadas para ser uma escola de inclusão, trazendo mais tranquilidade e conforto para os alunos inclusos, mas, sabe se que essa não é uma realidade de todo o estado e nem do pais em geral, no Brasil muitos estados ainda não conseguiram adequar todas as suas unidades seguindo o padrão exigido para que a unidade se torne uma escola de inclusão, mas, aos poucos o Brasil vai avançando em direção a padronização de todas as escolas.

Beyer (2006, p. 11), diz que:

O grande obstáculo, quando pensamos na criança com necessidades especiais, situa-se no isolamento frequente que vivencia na família, na vida escolar ou na vida em sociedade. $O$ isolamento, na ótica vygotskiana, não constitui apenas um problema social ou ético, porém representa uma faceta psicossocial muito delicada.

Faz se necessário também saber e entender quais os termos corretos para nos referir a determinadas deficiências, pois, muitas das vezes utilizar o termo errado pode deixar a criança ou até mesmo os pais constrangidos, usar o termo incorreto muitas das vezes pode ser entendido como preconceito ou até mesmo como forma de zombar da pessoa com deficiência isso em qualquer ambiente.

Sem a estrutura adequada para recebê-los fica muito difícil para que os professores possam trabalhar com os alunos inclusos, e isso faz com que o aluno seja excluído do da sociedade. Mas se as escolas estiverem bem adequadas para receber os alunos inclusos e os profissionais esteja capacitado, isso ajudaria e muito nesse processo de inclusão dos alunos com deficiência e faria com que os alunos e seus familiares se sintam inseridos na sociedade.

Outra coisa que deve ser bem trabalhado nas escolas é o preconceito dos demais alunos com os alunos inclusos, assim como disse em uma entrevista Leandra uma aluna de 10 anos de uma escola na cidade de Salvador "Um dia abracei um colega 
autista e me disseram que eu tinha encostado em uma pessoa doente", algo muito triste de se ouvir, por isso deve se trabalhar muito a questão do preconceito para que isso não venha a acontecer e que os alunos com deficiências e seus pais possa se sentir acolhidos por todos na escola.

Com a promulgação da Constituição Federal do Brasil (1988), e com a criação e regulamentação da Lei de Diretrizes e Bases da Educação Nacional/LDB, Lei №. 9.394, de 20 de dezembro de 1996. Onde as pessoas portadoras de deficiência passaram a ter todo o direito de acesso e permanência no espaço escolar, devendo ser garantido uma educação de qualidade a todos os alunos.

Olhando por esse lado, o processo de inclusão nas escolas ganhou grandes contribuições com a Constituição Federal (1988) que garante, em seu Artigo 205, a inclusão de todas as pessoas com deficiência no âmbito social e escolar:

A educação, direito de todos e dever do Estado e da família, será promovida e incentivada com a colaboração da sociedade. Visando o pleno desenvolvimento da pessoa, seu preparo para o exercício da cidadania e sua qualificação para o trabalho (BRASIL, 2013, p. 34).

Diante deste cenário de inclusão a escola deve garantir o acesso e a permanência de todos os alunos com deficiência nas salas de aula na unidade valorizando acima de tudo as diferencias de cada aluno, e em seu currículo de ensino garantir uma metodologia que venha a contemplar todos os alunos de forma igualitária e sem distinção.

\section{INCLUSÃO NA ATUALIDADE}

Percebe se que o tema inclusão está sendo muito discutido nos últimos anos estão tratando o tema com um pouco mais de seriedade, nota se também que o que mais se discute são formas de aproximar o poder público da sociedade e a discriminação sofrida pelas pessoas com deficiência no seu dia a dia, discriminação essa que muitas vezes promovida até de forma inocente por falta de conhecimento de como se referir a uma pessoa com deficiência, por este motivo orienta as que quando for se referir ou 
se dirigir a uma pessoa com deficiência utilizar sempre o nome da pessoa para evitar constrangimento da pessoa com o mau uso de termos incorretos.

Hoje em dia esse processo de inclusão vem sendo melhorado e muito, os professores além de receberem formações complementares através das secretarias de educação, passam a receber uma matéria especifica na grade curricular dos cursos superiores, principalmente o curso de Pedagogia, que é a matéria de Libras (Linguagem dos Surdos e Mudos), que já vai auxiliar e muito o professor em sala de aula caso venha a trabalhar com alunos com deficiência auditiva.

Como a pessoa com deficiência também é um ser humano como qualquer um, então não se pode permitir que sejam tratados de forma preconceituosa ou excluídas do convívio social onde todos tem esse direito constitucional, tem surgido muitas pessoas e grupos engajados na luta contra qualquer forma de discriminação e exclusão como a que ocorre com os portadores de deficiências.

Pessoas como Mantoan (2005, p. 24) que cita a escola como criadora de uma sociedade mais justa e dar oportunidade para todos. Segundo ela "Na escola inclusiva professores e alunos aprendem uma lição que a vida dificilmente ensina: respeitar as diferenças".

Hoje em dia é mais fácil uma criança conviver com as diferenças do que um adulto que já teve a sua mentalidade formada e quase sempre levando em consideração que o diferente é ruim, as crianças ainda estão em formação tanto corporal como sua mentalidade do que é certo e errado e como a escola é um local onde o aluno convive com todos os tipos de diferenças entre eles, por isso estão mais suscetível a aceitar as outras pessoas mesmo com suas diferenças, pois, na escola todos são iguais e recebem a mesma atenção, garantindo assim o direito de todos. (MANTOAN, 2005).

A Constituição de 88 (art.205) garante o acesso de todos a um ensino de qualidade, sendo que portadores de Necessidades Especiais devem receber um melhor atendimento que garanta ao aluno especial uma escola Regular com ensino de qualidade e de muito respeito com as diferenças e esse respeito às diferenças deve 
ser trabalhado dês dos anos iniciais nas escolas, para que as crianças já cresçam sabendo respeitar as diferenças entre eles.

\section{CONSIDERAÇÕES FINAIS}

O artigo visa compreender melhor o processo de inclusão dos alunos com deficiência nas escolas regulares e após os estudos e pesquisas nas obras citada na fundamentação teórica, pode ser observado que este processo iniciou se há muitos anos atrás e vem se modificando a cada ano buscando melhorar ainda mais esses atendimentos aos alunos com deficiências, porém, muito ainda precisa ser feito, no estado de Mato Grosso percebe se que as escolas estão preparadas estruturalmente para receber esses alunos, porém, os profissionais contratados para atender esses alunos em especial são temporário o que dificulta muito o atendimento dos alunos com deficiência nas escolas, porque nem sempre os mesmos profissionais serão contratados no ano seguinte, pois, a escolha é feita através de processo seletivo no estado e nos municípios e o gasto com isso é muito alto, e para resolver esse problema o que deve ser feito para melhorar isso é a regulamentação do cargo denominado no estado de Mato Grosso como CAD (Cuidador de Alunos com Deficiências) e assim poderem realizar concursos públicos para esse cargo o que diminuiria e muito os gastos com formações para esses profissionais, pois, os mesmos sendo concursados permaneceram por muitos anos na rede e não precisara passar pelas mesmas formações todo ano, isso melhoraria muito o atendimento dos alunos com deficiências, pois, tanto a escola como a família terá a certeza que a criança estará na responsabilidade de um profissional com experiência e formação para desempenhar um bom trabalho com o aluno incluso levando-o a seu pleno desenvolvimento dentro da unidade escolar.

Com esse processo seletivo as secretarias de educação tanto do estado como dos municípios tem uma rotatividade muito grandes quanto a esses profissionais, pois, esse processo seletivo só é valido para o ano letivo corrente e para o próximo ano letivo o profissional deverá passar por todo o processo novamente o que desmotiva muitos deles a continuar trabalhando nessa função, mas, para amenizar essa situação enquanto não sai a regulamentação do cargo para a realização do concurso, as 
secretarias de educação poderá aumentar o prazo de validade do processo seletivo de 1 (um) para 2 (dois) anos letivos consecutivos, fazendo assim valer apena todo o esforço do profissional para ser aprovado nesse processo seletivo, mas, esse processo vem se mostrando pouco vantajoso, pois, se tornou muito burocrático na questão de contratação, existem escolas que mesmo depois de meses após o início das aulas ainda não tem alguns professores e nem mesmo CAD, por causa da burocracia, coisa que não acontecia com o processo anterior ao processo seletivo, onde tinha o nome de contagem de pontos onde era feito pela equipe gestora de cada escola, e os profissionais contavam ponto na escola onde queriam trabalhar, mas, como já foi dito antes para melhorar este processo principalmente no que tange ao aluno com deficiência é o regulamentação do cargo de CAD e a realização de concursos.

E para concluir pode se afirmar que $o$ artigo conseguiu atingir o seu objetivo que era de compreender o processo de inclusão dos alunos com deficiências nas escolas regulares e encontrar formas de melhorar esse processo ainda mais, ficando assim a regulamentação do cargo e o concurso público como formas de melhorar esse processo.

\section{REFERÊNCIAS}

ALVES, D. O. INCLUSÃO, Revista da Educação Especial, 2007, P. 4, Disponível em:<http://portal.mec.gov.br/seesp/arquivos/pdf/rev4web.pdf>. Acesso em: $13 / 05 / 2019$

BEGUOCI, L. Inclusão - Revista Nova Escola. Ed. № 319. São Paulo: 2019

BEYER, H. O. A EDUCAÇÃo INCLUSIVA, Revista da Educação Especial, 2006, P.11, Disponível em: $<\mathrm{http}: / /$ portal.mec.gov.br/seesp/arquivos/pdf/revistainclusao2.pdf $>$. Acesso em: $13 / 05 / 2019$ 
BRASIL. Constituição (1988. art. 206). Constituição da República Federativa do Brasil. Brasília, DF: Senado. 1988. Disponível em: <http://www.planalto.gov.br/ccivil_03/constituicao/constituicao.htm> Acesso em $15 / 05 / 2020$

ECA- Estatuto da Criança e do Adolescente Criado pela Lei Federal de № 8.069 de 13 de Junho de 1990. Disponível em: <https://www.chegadetrabalhoinfantil.org.br/wpcontent/uploads/2017/06/LivroECA_2017_v05_INTERNET.pdf> Acesso em $15 / 05 / 2020$

MACIEL, M. R. C. Portadores de Deficiência a questão da inclusão social, São Paulo 2000 ,

Disponível

em;

$<$ https://www.scielo.br/scielo.php?script=sci_arttext\&pid=S0102-

88392000000200008> Acesso em 13/05/2020.

MANTOAN, M. T. E. Inclusão Escolar. O que é? Por Quê?, Como Fazer?. Editora Moderna. Campinas $\quad$ SP. $\quad$ Disponível em $<$ https://acessibilidade.ufg.br/up/211/o/INCLUS\%C3\%83O-ESCOLARMaria-TeresaEgl\%C3\%A9r-Mantoan-Inclus\%C3\%A3o-Escolar.pdf?1473202907>. Acesso em: 13/05/2019.

REIS, R. L. dos.; ROSS, P. R. A inclusão do aluno com deficiência intelectual no Ensino Regular, Disponível em:<http://www.diaadiaeducacao.pr.gov.br/portals/pde/arquivos/2216-8.pdf>. Acesso em: 13/05/2019

RIBEIRO, L. O. M. Revista Educação Arte é Inclusão, Vol 13 ํo 01, Janeiro/Abril, 2017 Disponível em; $<w w w . r e v i s t a s . u d e s c . b r / i n d e x . p h p / a r t e i n c l u s a o / a r t i c l e / d o w n l o a d / 9287 / p d f>$. Acesso em 04/04/2019

Secretaria de Educação Especial/MEC, INCLUSÃO, Revista da Educação Especial, Desenvolver a Educação Inclusiva, Vol 06 № 2. Julho/Outubro 2008, Disponível em: 
$<$ http://www.crianca.mppr.mp.br/arquivos/File/publi/revista_inclusao/revista_inclusao _06_mec_jul2008.pdf>. Acesso em 04/04/2019.

URBANO, P. R. Diversidade - Revista Nova Escola. Ed. № 317. São Paulo: Novembro. 2018.

Enviado: Julho, 2020.

Aprovado: Janeiro, 2021. 